\title{
A Design Study on the Torsion Vibration of the Vehicle Powertrain
}

\author{
Tieshan Zhang ${ }^{1, a^{*}}$, Mingsong $\mathrm{Li}^{1, \mathrm{~b}}$ \\ ${ }^{1}$ School of mechanical eng. , Nanjing Univ. of Science and Technology ,Nanjing 210094,China \\ a *E-mail: zhangtieshan@njust.edu.cn, ${ }^{b} E$-mail: limingsongYXD@163.com
}

Keywords: transmission system; automobile; torsion vibration; design research

Abstract: Take a vehicle mounted DMF(dual mass flywheel) drive system as an example, Inherent characteristics and response characteristics of automotive transmission system is calculated by the simulation software. The results show that reduce the stiffness $\mathrm{K}_{8}$ between DMF second quality and transmission gearbox input shaft, which will improve the performance of vibration reduction on the idle speed condition. The low stiffness $\mathrm{K} 8$ is realized by using a clutch torsion vibration damper on the idle condition.

\section{Introduction}

The torsion vibration of the vehicle power train is solved by the reasonable design of the flywheel and clutch, which between the engine crankshaft and the transmission gearbox input shaft. There are two solutions, one way is to design a reasonable clutch torsion damper (CTD), the other method is to replace CTD with DMF. The DMF has many advantages in comparison to CTD and has been widely used in the diesel vehicle[1,2].Driveline torsion vibration phenomena mainly has three issues[1]:1)The vibration and noise of the power train at idle speed, driving and parking conditions;2)The excitation of engine and power train to cause torsion resonance;3)Dynamic conversion in driving process causes torsion vibration shock. At present, there are many studies on the power train of DMF. On the basis, whether there is a better solution for the power train, the author will discuss in this article.

In order to find a more reasonable solution for the torsion vibration of the drive system, based on the design of the transmission system of the DMF, the influence of the stiffness between the first mass of DMF and the output end of the crankshaft and between the second mass of DMF and transmission gearbox first axis will be discussed.

\section{Torsion Vibration System Modeling}

In order to study the characteristics of torsion vibration system, the system model is firstly established. In study natural frequency of vibration and main models, the parts will be simplified as inertia disc, connect the inertia disc with a certain stiffness of elastic shaft, ignore the effect of damping. In the study, a four-cylinder engine power source is matched with the power train as the research object, and the model of the system is established, which is based on the idle speed and driving condition, as shown in Fig. 1 and Fig. 2.

The physical meaning of the symbols in Fig. 1 and Fig. 2 as shown in table 1. According to the mechanical model of figure 1 and figure 2,we can establish the free vibration Eq. (1) in the idle and the driving condition and the vibration differential Eq. (2) under the engine excitation:

$$
\begin{aligned}
& {[J]+[K]\{\theta\}=\{0\}} \\
& {[J]\{+[K]\{\theta\}=\{T\}}
\end{aligned}
$$

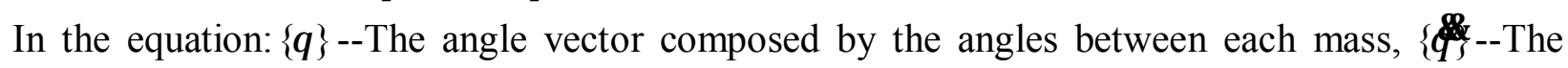
angular acceleration vector composed by angular acceleration of each mass, $\{\mathrm{T}\}$--the excitation torque vector, $[J]$--The inertia matrix composed by the inertia of each mass, $[K]$--The stiffness matrix composed by the stiffness of each inertia. As long as appropriate to a given mass of moment of inertia and torsion stiffness, the established mechanical model can describe drive train system of CTD, and also describe the drive train system of DMF instead of CTD. 
Eq.(1), Eq.(2), and the physical meaning of the parameters in Fig.1 and Fig.2 are shown in Table 1.

Table 1 physical meaning of moment of inertia and torsion stiffness

\begin{tabular}{|c|c|c|c|}
\hline $\begin{array}{l}\text { Moment } \\
\text { of inertia }\end{array}$ & Physical meaning [kg. $\left.\mathrm{m}^{2}\right]$ & $\begin{array}{l}\text { Torsion } \\
\text { stiffness }\end{array}$ & Physical meaning [Nm/degree] \\
\hline $\mathrm{J}_{1}$ & Rotary inertia of belt wheel & $\mathrm{K}_{1}$ & $\begin{array}{l}\text { Torsion stiffness of rubber shock } \\
\text { absorber }\end{array}$ \\
\hline $\mathrm{J}_{2}$ & $\begin{array}{l}1 / 2 \text { rotary inertia of crankshaft free end } \\
\text { and rotary inertia of rubber damper }\end{array}$ & $\mathrm{K}_{2}$ & $\begin{array}{l}\text { Torsion stiffness of crankshaft free end } \\
\text { torsion stiffness }\end{array}$ \\
\hline $\mathrm{J}_{3}$ & $\begin{array}{l}\text { Rotary inertia of engine first cylinder } \\
\text { crankshaft connecting rod }\end{array}$ & $\mathrm{K}_{3}$ & Torsion stiffness of crank throw toggle 1 \\
\hline $\mathrm{J}_{4}$ & $\begin{array}{l}\text { Rotary inertia of engine second cylinder } \\
\text { crankshaft connecting rod }\end{array}$ & $\mathrm{K}_{4}$ & Torsion stiffness of crank throw toggle 2 \\
\hline $\mathrm{J}_{5}$ & $\begin{array}{l}\text { Rotary inertia of engine third cylinder } \\
\text { crankshaft connecting rod }\end{array}$ & $\mathrm{K}_{5}$ & Torsion stiffness of crank throw toggle 3 \\
\hline $\mathrm{J}_{6}$ & $\begin{array}{l}\text { Rotary inertia of engine fourth cylinder } \\
\text { crankshaft connecting rod }\end{array}$ & $\mathrm{K}_{6}$ & $\begin{array}{l}\text { Torsion stiffness of the crankshaf } \\
\text { flywheel }\end{array}$ \\
\hline $\mathrm{J}_{7}$ & $\begin{array}{l}1 / 2 \text { rotary inertia of engine crankshaft, } \\
\text { and rotary inertia of first mass of DMF }\end{array}$ & $\mathrm{K}_{7}$ & Torsion stiffness of DMF \\
\hline $\mathrm{J}_{8}$ & $\begin{array}{l}1 / 2 \text { rotary inertia of gearbox input shaft, } \\
\text { second mass of DMF, and the clutch }\end{array}$ & $\mathrm{K}_{8}$ & Torsion stiffness of clutch \\
\hline $\mathrm{J}_{9}$ & Rotary inertia of clutch & $\mathrm{K}_{9}$ & $\begin{array}{l}\text { Torsion stiffness of gearbox input shaf } \\
\text { and the gear equivalent }\end{array}$ \\
\hline $\mathrm{J}_{10}$ & $\begin{array}{l}\text { Rotary inertia of the gearbox input shaft } \\
\text { and input gear }\end{array}$ & $\mathrm{K}_{10}$ & $\begin{array}{l}\text { Torsion stiffness of gearbox middle shaf } \\
\text { and the gear equivalent }\end{array}$ \\
\hline $\mathrm{J}_{11}$ & $\begin{array}{l}\text { Rotary inertia of the gearbox middle } \\
\text { shaft and intermediate shaft gear }\end{array}$ & $\mathrm{K}_{11}$ & $\begin{array}{l}\text { Torsion stiffness of gearbox output shaft } \\
\text { and the gear equivalent }\end{array}$ \\
\hline $\mathrm{J}_{12}$ & $\begin{array}{l}\text { Rotary inertia of the gearbox output shaft } \\
\text { and output gear equivalent }\end{array}$ & $\mathrm{K}_{12}$ & $\begin{array}{l}\text { Torsion stiffness of the first shaf } \\
\text { equivalent of the gearbox shaft }\end{array}$ \\
\hline $\mathrm{J}_{13}$ & $\begin{array}{l}\text { Equivalent rotational inertia of the first } \\
\text { shaft of the universal gearbox shaft }\end{array}$ & $\mathrm{K}_{13}$ & $\begin{array}{l}\text { Torsion stiffness of the second shaf } \\
\text { equivalent of the gearbox shaft }\end{array}$ \\
\hline $\mathrm{J}_{14}$ & $\begin{array}{l}\text { Rotary inertia of the first shaft of } \\
\text { universal gearbox shaft }\end{array}$ & $\mathrm{K}_{14}$ & $\begin{array}{l}\text { Torsion stiffness of main reducer } \\
\text { equivalent }\end{array}$ \\
\hline $\mathrm{J}_{15}$ & $\begin{array}{l}\text { Rotary inertia of the second shaft of } \\
\text { universal gearbox shaft }\end{array}$ & $\mathrm{K}_{15}$ & Torsion stiffness of half shaft equivalent \\
\hline $\mathrm{J}_{16}$ & $\begin{array}{l}\text { Rotary inertia of differential mechanism } \\
\text { and half shaft equivalent }\end{array}$ & $\mathrm{K}_{16}$ & Torsion stiffness of wheel equivalent \\
\hline $\mathrm{J}_{17}$ & Rotary inertia of body equivalent & & \\
\hline
\end{tabular}

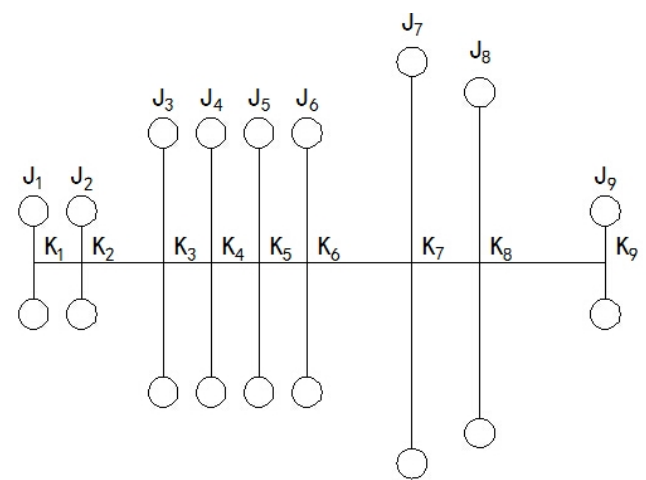

Fig. 1 Simplified mechanical model of torsion vibration in idle condition

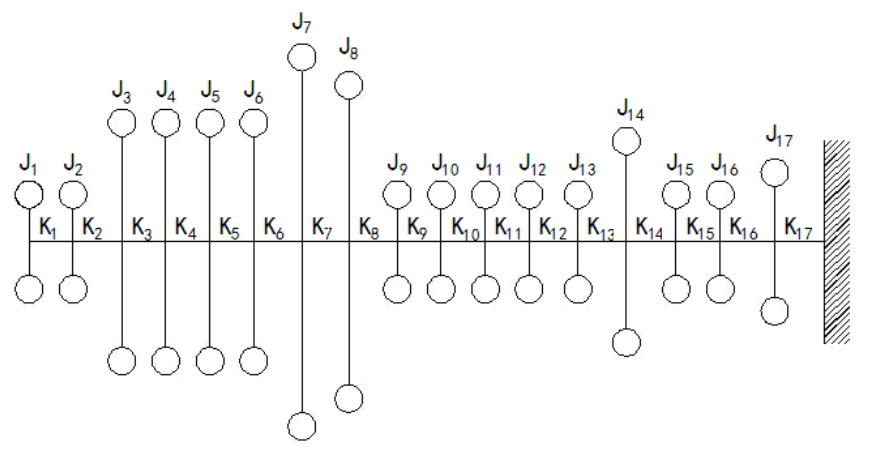

Fig. 2 Simplified mechanical model of torsion vibration in driving condition 


\section{Torsion vibration matching simulation for drive system}

According to the analysis of reference [1-3], the factors that influence the matching of the power train have the stiffness, inertia and damping, and the stiffness has a greater impact. In addition, the adjustment of rigidity is more easy to achieve, therefore, the stiffness problem will be mainly discussed here. The simulation research object is the model of reference [1], the engine idle speed is about $800 \mathrm{r} / \mathrm{min}$, that is, the excitation frequency is about $26.7 \mathrm{~Hz}$. As long as the natural frequency of the drive train system does not coincide with the frequency of the excitation, the system can avoid the resonance.

Idle condition. Analysis shows that the stiffness of connection between power and transmission system need to be as low as possible in the idle condition. It can be considered in two parts to achieve this goal. First try to add a torsion vibration damper to the clutch between the second mass of DMF and the transmission gearbox input shaft. Using model of Fig.1 and Eq. (1), the stiffness $\mathrm{K} 8$ set to 10 , and then the simulation by Matlab and Adams, results of are respectively shown in Fig.3, Fig.4. The PART-9, PART-10, PART-18, PART-8, respectively, on behalf of the first mass of DMF, the second mass of DMF, clutch and transmission gearbox shaft, wheel.

From Fig. 3 it can be seen that the main vibration mode of $\mathrm{K}_{8}=10$ meets the requirements, and the excitation vibration frequency is avoided. From Fig. 4 it can be seen that the vibration acceleration of the transmission gearbox input shaft is less than $10 \%$ of the second mass of DMF. This shows that the vibration acceleration of the $\mathrm{K}_{8}=10$ scheme is greatly attenuated at idle speed.

But, we can also improve the idle performance by adjusting the $\mathrm{K}_{7}$, which is also a solution to the problem of optional. To this end, make the $\mathrm{K}_{7}=10$, respectively, MATLAB and ADAMS simulation calculation, the results are: 2 th order frequency, 3 th order frequency, 4th order frequency, are 1.6, 246.2, 272.2, the main vibration mode to meet the requirements, and also to avoid the excitation vibration frequency. In Fig. 5, the response of the PART_10 is much higher than that of $\mathrm{K}_{8}=10$, and it has a low frequency oscillation mode, which is disadvantageous to the power train. This shows that the vibration effect of $\mathrm{K}_{7}=10$ is less than that of $\mathrm{K}_{8}=10$.

From what has been discussed above, in the idle condition, in order to better match the transmission

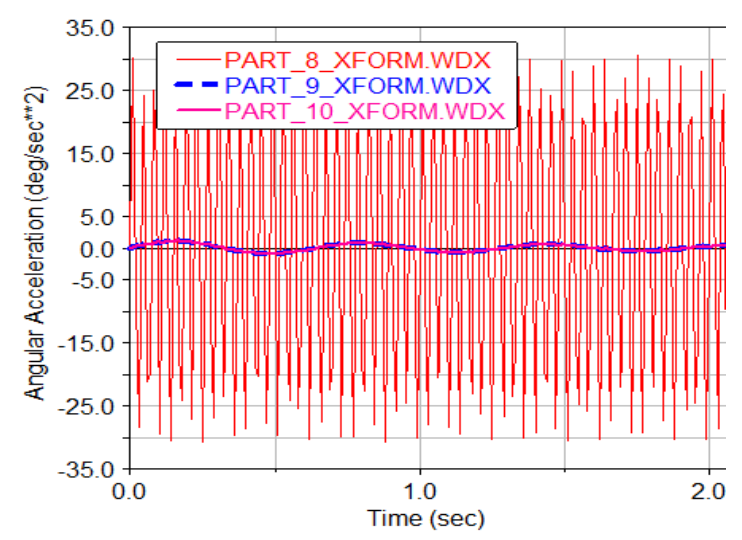

Fig. 5 vibration acceleration of the input shaft of the $\mathrm{K}_{7}=10$ gearbox 
system, We can solve the problem by using the $\mathrm{K}_{8}$ as low as possible.

Driving condition. Under the driving condition, Based on mechanical model and mathematical model (2) which are established at the second chapter, respectively, Matlab and Adams simulation tools were used to calculate the inherent characteristics and the response of the excitation. The analysis shows that the solution of the $\mathrm{K} 8$ values as low as posible can be better matched with the power train. Whether this conclusion is suitable for driving conditions, it also needs to be determined. Simulation analysis under driving conditions, K8 stiffness simplified as follows: Considering that the $\mathrm{K} 8$ is a very small number, the clutch is added to a set of the coil spring of low stiffness to achieve. In driving conditions, this group of low stiffness spring has and circle (corresponding torsion stiffness is very large), namely the stiffness of $\mathrm{K} 8$ between the second mass of DMF and the transmission gearbox input shaft is still large, that is, with the object of study is 19588 .

The 3 order, 4 order and 5 order natural frequencies are obtained by simulation calculation $12.8,158,246.2$, the corresponding vibration mode meet the requirements, and the excitation vibration frequency is avoided. The excitation is still the sine excitation unit of the engine's output end, and the vibration acceleration of the output of the transmission gearbox input shaft is shown on the curve of PART_10 in Fig. 6.

Integrating simulation results in idle condition and driving condition, $\mathrm{K}_{8}$ can be used for the matching scheme of power train, so that we can better solve the torsion vibration of drive train system.

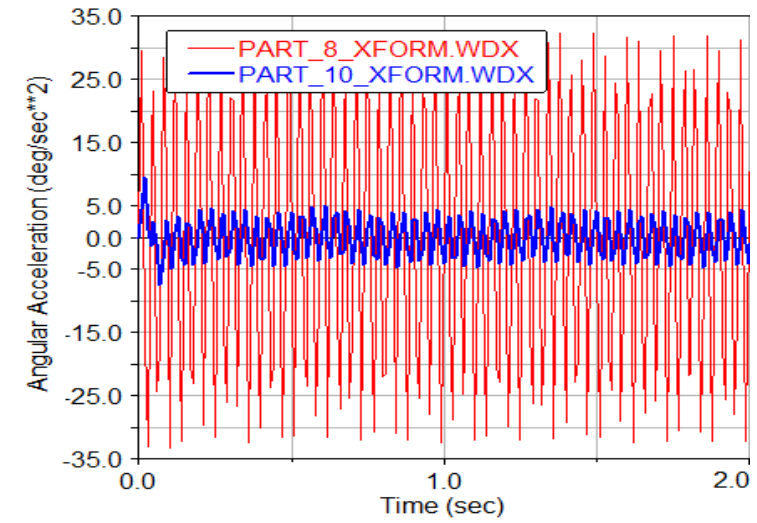

(a) the vibration acceleration of the gearbox shaft and the first mass of the DMF

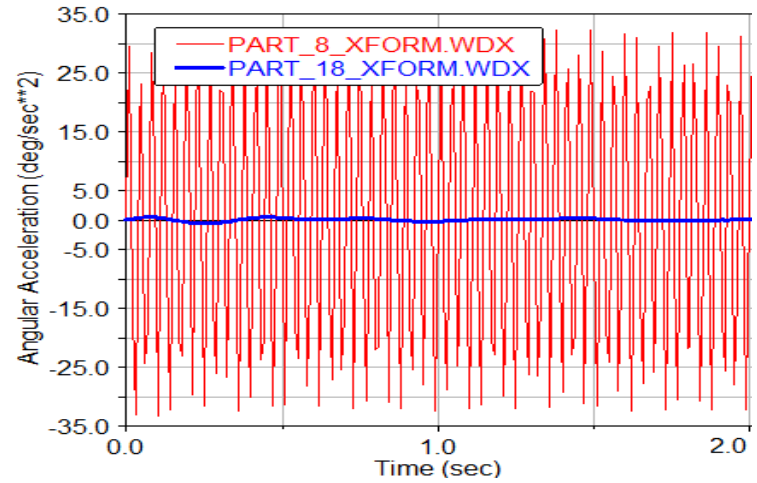

(b) the vibration acceleration of the wheel and the first mass of DMF

Fig. 6 vibration acceleration of driving condition

\section{Simulation model validation}

Whether the simulation results of the second chapter are credible, and the results will be verify by use of results the study of the [1]. The results of the simulation are compared with the results of reference [1], and the results are shown in Table 2.

Table 2 Comparison of the inherent torsion characteristics before 5 order

\begin{tabular}{|c|c|c|c|c|c|c|c|}
\hline \multicolumn{4}{|c|}{ Idling condition } & \multicolumn{4}{|c|}{ Driving condition } \\
\hline Order & $\begin{array}{l}\text { Natural } \\
\text { frequency } \\
{[\mathrm{Hz}]}\end{array}$ & $\begin{array}{c}\text { Values of } \\
\text { Reference[1] } \\
{[\mathrm{Hz}]}\end{array}$ & $\begin{array}{c}\text { modes } \\
\text { comparison }\end{array}$ & Order & $\begin{array}{c}\text { Natural } \\
\text { frequency } \\
{[\mathrm{Hz}]}\end{array}$ & $\begin{array}{c}\text { Values of } \\
\text { Reference[1] } \\
{[\mathrm{Hz}]}\end{array}$ & $\begin{array}{c}\text { modes } \\
\text { comparison }\end{array}$ \\
\hline & - & - & - & 1 & 1.3 & 1.272 & almost \\
\hline 2 & 10.2 & 10.24 & almost & 2 & 2.9 & 2.883 & almost \\
\hline 3 & 246.2 & 246.2 & almost & 3 & 12.8 & 12.82 & almost \\
\hline 4 & 272.2 & 272.2 & almost & 4 & 158 & 157.9 & almost \\
\hline 5 & 440.4 & 440.4 & almost & 5 & 246.2 & 246.2 & almost \\
\hline
\end{tabular}

Table 2 shows that the author's simulation results are in good agreement with the results of reference[1], proving this paper established the model and the simulation results are credible. 


\section{Implementation of matching scheme}

The design of the torsion vibration damping performance of the power train is related to the various parts of the moment of inertia, stiffness and damping [1-3], that is, the design of power train is reasonably determine the corresponding moment of inertia, stiffness and damping. Due to torsion vibration damping mechanism generally used small damping, for the moment of inertia has been basically determined by power train, it is important to determine the torsion stiffness of the various parts . that is, a reasonable torsion stiffness obtained good torsion vibration damping performance.

According to the simulation analysis results in the third chapter we can be found, on the basis of adopting DMF to solve torsion vibration, the torsion stiffness of $\mathrm{K}_{8}$ is reduced. When the main vibration mode in the idle mode is reasonable, it can make the vibration acceleration peak of the transmission gearbox shaft is significantly lower.

According to general design method of transmission system of DMF, only DMF and clutch are located between the engine crankshaft flange and the transmission gearbox input shaft, namely, to improve transmission system performance, improving the two-part is only available.

According to the analysis in the third chapter shows that, if maintain $\mathrm{K}_{8}$ unchanged and let $\mathrm{K}_{7}$ is equal to 10 or very small values, the only possible solution is the DMF will be changed to three mass flywheel, namely increase a torsion elastic device between the crankshaft flange and the first mass of DMF. However, the response characteristics of the structure are similar to DMF, and higher peak oscillations of the low frequency is very bad for the power train. Therefore, this scheme is unfavorable and infeasible.

Since the clutch is present between the second mass of DMF and the transmission gearbox input shaft, the power train of DMF is currently equipped with the clutch that does not carry a torsion damper. To achieve a $\mathrm{K}_{8}=10$ or a very small number, we can added a very small torsion vibration damping mechanism in clutch. In order to ensure the driving train system can still maintain a good torsion vibration characteristics, we can use the helical spring as the elastic element of the torsion vibration damper. Namely, the clutch of the torsion vibration mechanism doesn't work in driving condition, the state of the coil spring is in a circle. While reducing the stiffness of $\mathrm{K}_{8}$ will affect the main vibration mode of the driving mode, the $\mathrm{K}_{8}=10$ or very small values is design for idle mode, in the driving condition, the coil spring of CTD and circle, then the $\mathrm{K}_{8}$ between the second mass of DMF and the transmission gearbox input shaft is still maintained for $10^{4}$ orders of magnitude. Therefore, realization scheme of reasonable matching of drive train system is to use the conventional design method to match DMF, and the clutch is designed with idle torsion vibration damper (Torsion vibration damping stiffness as low as possible).

\section{Conclusion}

Through the analysis of this paper, a reasonable matching solution of power train is: The DMF is designed in conventional method, at the same time, adjusting the torsion stiffness between the second mass of DMF and the transmission gearbox input shaft, the vibration acceleration in idle condition will be reduced, and will can meet the requirements in driving condition. The adjustment of the torsion stiffness between the second mass of DMF and the transmission gearbox input shaft is realized by adding the idle torsion vibration damper in the clutch.

\section{References}

[1] Guangming Zhao, Research on Nonlinear Performance of Torsional Vibration Reduction of Circumferential Spring DMF, Wuhan University Of Technology, Wuhan, 2013.

[2] Wei Li, Research on the Method and the Performance of Isolation of Torsional Vibration of DMF-CS Based on the Vehicle Power Train,Jilin University,Changchun,2009.

[3] Mingxiang Tang, Xinlong Tang, Guijun Dong, Analysis of Influence of Parameters of Non-Linearly Elastic DMF on Vibration Reduction Effect. 30(2010) 102-105. 